\title{
O processo do conhecimento/pesquisa no ensino de história
}

\author{
Helenice Ciampi*
}

\begin{abstract}
RESUMO
0 processo de conhecimento histórico e sua adequaçã̃o ao ensino-aprendizagem, são aqui tratados a partir das concepções que fundamentam uma proposta de trabalho que procura estabelecer o dialogo de uma pedagogia da inclusão, que visa a prática da cidadania e 0 respeito às diferenças, com a realidade da exclusão, que aponta justamente para a distância entre a teoria e a prática. Estando atenta a esta contradição, o artigo objetiva refletir sobre conceitos e concepções que poderiam orientar a proposta de curso de cada professor de professor de história, tais como: a relação e diferenciação entre História e Memória ( pois o tempo histórico é o das mudanças; o da memória coletiva, da permanência); Cultura; Representação (cuja noção permite articular três modalidades de relação com o mundo social); Leitura; Competências (especialmente a relacional); e, a Aprendizagem Significativa.
\end{abstract}

Palavras-chave: conhecimento histórico; cultura; representação; competências; aprendizagem significativa; ensino de história.

\section{Introdução}

0 artigo abordará o processo de estudo/pesquisa que tenho desenvolvido na disciplina metodologia do ensino de História. Às questões colocadas pela produção do conhecimento histórico foram articulados temas e conceitos recorrentes no processo ensino-aprendizagem.

Minha trajetória profissional expressa uma ligação direta com a tessitura dos saberes históricos escolares, na relação entre a História e a Educação. Exprime o desafio de articular dois campos do conhecimento: 0 da história e 0 da educação, num processo contínuo de envolvimento com a prática docente

\footnotetext{
* Professora de Metodologia do Ensino de História da PUC/SP.
} 
e seus problemas teórico-metodológicos. Expressa, portanto, a permanente pesquisa e estudo de obras que possam fundamentar minha prática e embasar "intuições". Questiono o discurso teórico "vazio", o verbalismo excessivo, distanciado da realidade educacional/escolar que nos cerca, sobretudo quando ignora a exclusão sócio-pedagógica em que vive, hoje, o professor.

Propõe-se, atualmente, uma pedagogia da inclusão, alicerçada nas propostas da Lei de Diretrizes e Bases (LDB/1996), das Diretrizes Curriculares para todos os níveis de ensino, e dos Parâmetros Curriculares Nacionais (PCN1997e 1998). Sem dúvida, todos esses documentos constituem avanços nas discussões teórico-metodológicas. Mas, na prática, a política educacional neutraliza possíveis avanços, pois não sinaliza no sentido de mudanças estruturais, tais como salário adequado, formação consistente e condições de trabalho que possibilitem viabilizar as orientações sugeridas.

Esta introdução não significa uma colocação "politicamente correta" ou o desabafo de um profissional em contato "com as bases", mas indignação com uma permanência histórica: a pedagogia da inclusão x realidade da exclusão de alunos e professores. Se por uma lado, a primeira aponta para uma proposta de prática da cidadania e do respeito às diferenças, por outro, a prática aumenta o fosso que separa tal proposta das desigualdades e intolerâncias sociais, pois, por ironia, convive com uma acentuada desigualdade que reforça assustadoramente a idéia de que o "inchaço retórico é incompativel com a pobreza das práticas".

Aqueles profissionais, que procuram ou têm uma prática conseqüente, desiludidos, estão sendo expulsos da escola, por falta de condições dignas de trabalho, pela violência do cotidiano escolar, pela redução de carga horária, pelo aumento do número de alunos em sala de aula e pela desvalorização do seu papel social e profissional. Este panorama talvez esclareça minhas opções de pesquisa e estudo neste período. Expressam, essencialmente, o exercício de refletir os procedimentos que orientam uma prática coerente com os princípios que a fundamentam; tentando viabilizar os conceitos selecionados e aceitos teoricamente.

Paralelamente, procuro acompanhar e orientar práticas efetivas, profissionais de história que criam saberes conjuntamente com seus alunos. Estas práticas precisam ser recuperadas na sua historicidade $e_{\vartheta}$ no limite, delinear o significado de tais práticas para todos os envolvidos.

${ }^{1}$ Editorial do Jornal- Bolando Aulas de História, maio de 2000. 


\section{Concepções que fundamentam minha proposta}

Meu processo de pesquisa teve inicio formal com o livro Ensino de História: revisão urgente, fruto de um trabalho coletivo de profissionais da história preocupados com a prática conseqüente no ensino da história. Lançava as bases de uma proposta metodológica aliando docência e pesquisa. Publicado pela editora Brasiliense nos anos oitenta, foi, atualmente, reeditado pela EDUC/INEP. ${ }^{2}$ Assinala as diretrizes de uma proposta que venho amadurecendo para ampliar a compreensão dos princípios básicos, articulando-os com os procedimentos teórico-metodológicos que embasam a prática do professor pesquisador.

Há diferentes maneiras de conceber a natureza do conhecimento humano e de conceber e apreender o conhecimento histórico. A diversidade de pressupostos e perspectivas nos permite confrontar diferentes posições na sua organização teórica e procedimentos metodológicos. Desta forma, o permanente questionamento teórico- metodológico existente na construção da teoria do conhecimento e da história deve ser pensado quando se indaga o que é ensinar história hoje, 'não metodologia pela metodologia, mas uma reflexão necessária sobre a história que se faz e sobre a história a fazer'(Le GOFF, 1968, p. 229). As diferentes contribuições precisam ser discutidas e analisadas para possibilitar avançar nas questões de sua transmissão. As novas abordagens, objetos e problemáticas colocadas pela historiografia constituem parâmetros para a constituição dos procedimentos metodológicos de uma nova pratica pedagógica. ${ }^{3}$

Partindo do pressuposto da articulação entre a produção do conhecimento histórico e sua adequação para as questões do ensino em história, procuro ressaltar o trabalho de construção do historiador. A partir de um problema levantado sobre os dados colocados pelas vozes dos diferentes sujeitos, nas fontes investigadas, o historiador constrói sua interpretação. Assim, também, 0

2 CIAMPI, Helenice e outros. Ensino de história urgente. São Paulo, EDUC/INEP, 2000.

3 CIAMPI, Helenice. A História Pensada e Ensinada: da geração das certezas à geração das incertezas. São Paulo: EDUC/FAPESP, 2000, p.15 
professor deve pensar um problema a ser trabalhado com os seus alunos. Ao pensar o que fazer em uma série, é fundamental selecionar um tema e os assuntos que lhe permitam analisar/responder a problemática escolhida. Ressaltar os desdobramentos do ofício do historiador no trabalho do professor em sala de aula, bem como a preocupação com montagem do tema, a problematização, o trabalho de seleção, tratamento e confronto das fontes para compreensão e explicação do objeto de estudo. Ter o aluno e o professor como sujeitos históricos e do seu próprio conhecimento.

Para Adam Schaff, é na prática social que o sujeito conhece o objeto, na e pela sua atividade, qual seja, o "homem é na sua realidade o conjunto de suas relações sociais". 0 processo de conhecimento constitui uma relação particular entre sujeito e objeto, pois o objeto só é cognoscível quando o sujeito cognoscente participa do processo de produção do conhecimento, tornando-o uma "coisa para nós". ${ }^{4} 0$ conhecimento é um processo e não um dado pronto, acabado, definitivo.

Schaff questiona a concepção do conhecimento como reflexo fiel da realidade, livre de todo fator subjetivo. No conhecimento histórico, sujeito e objeto constituem uma totalidade; o conhecimento e o posicionamento do historiador estão sempre socialmente comprometidos. Questiona o caráter de verdade absoluta e homogeneizadora, pela qual o passado é cristalizado numa só perspectiva, impedindo o resgate de outras possibilidades da história. Parte da tese de que o conhecimento, assim como a verdade, é um processo; portanto, a história não encerra uma verdade absoluta, mas é constituída de verdades parciais e incompletas, sendo continuamente reescrita.

Conhecimento visto como diálogo entre conceitos e realidade social; como construção de significados e relações entre pessoas, idéias e objetos. Implica em uma forma de comunicação, uma vez que o significado construído expressa-se em práticas e representações, permitindo alterar a relação com 0 meio familiar e social.

0 processo de conhecimento, inclusive no espaço escolar, implica um movimento de relações recíprocas entre o sujeito que conhece e o objeto a ser conhecido, num dado contexto sócio-cultural. As relações que envolvem alunos, professor e conhecimento, no espaço escolar, são complexas: articulam

\footnotetext{
4 SCHAFF, Adam. História e Verdade. São Paulo: Martins Fontes, 1986, p.85.
} 
experiências, vivências, interesses, valores e expectativas diferenciadas. Nesse espaço, cruzam-se vozes e significados diversos, influindo no processo de construção do conhecimento. Daí a importância da interlocução, do diálogo dos alunos com o objeto/tema de estudo, orientado pelo professor.

As concepções mais tradicionais das ciências da natureza, que ainda vigoram no meio acadêmico e são amplamente aceitas na cotidianidade devido a ostensiva massificação do conhecimento, buscam as leis amplas e abrangentes que possam ser usadas para explicar a maior quantidade possível de fenômenos da mesma ordem. Por exemplo, a lei da gravidade se aplica em todo o globo terrestre, assim como a quaisquer corpos do universo. A história está preocupada em estudar e explicar as ações humanas no tempo. Busca o específico. Ė nosso princípio ter o conhecimento construído pelos historiadores como provisório (uma nova fonte e/ou interpretação pode alterá-lo), descontínuo (já que 0 historiador não deve ter a pretensão de estudar toda a história dos homens, em todos os aspectos, através dos tempos, pois corre o risco de abstrair as especificidades sociais) e seletivo (uma vez que o historiador elege o seu tema/ objeto, o seu problema e a forma de abordá-lo).

As inúmeras mudanças ocorridas antes mesmo da passagem do século 20 para 0 21, tais como a nova ordem mundial, a revolução tecnológica, 0 esfacelamento de instituições, práticas e paradigmas de análise, colocaram novas exigências para a educação. As questões de vida e morte, as histórias vividas, invadiram o nosso cotidiano, e a escola nem sempre os enfrenta em seu trabalho pedagógico. Para superar estas dificuldades, precisamos pensar e agir pelo princípio da inter/transdisciplinaridade, ligado à idéia de uma interação, negociação ética e política entre as diferentes áreas de conhecimento, e não a uma mera justaposição de conteúdos disciplinares. Ampliar os horizontes disciplinares pode nos auxiliar a reencontrar o sujeito e a traduzir um novo momento da história, frente à necessidade indispensável de interligações entre as áreas do conhecimento. ${ }^{5}$

0 desafio do volume de informações, produzido em função de novas tecnologias, implica pensar uma formação docente capaz de desenvolver, com os alunos, não só conceitos disciplinares, mas, sobretudo, outra ordem de

5 MORIN, Edgar. Os setes saberes necessários à educação do futuro. São Paulo: Cortez; Brasília, DF: Unesco, 2000. 
conteúdos, os procedimentais, incluindo as competências e, entre elas, a pesquisa e seleção de informações para resolver um problema e analisar, entre as possíveis soluções, a(s) mais adequada(s) ao seu contexto.

"É preciso pensar o aluno que temos hoje: por vezes mal alfabetizado, vivendo em um mundo de correrias e violência, um sujeito 'blip', aquele feito de fiapos de informações e vivências, bombardeado pelas imagens da mídia". ${ }^{6}$ Una criança ou jovem vivendo em um mundo globalizado, que se caracteriza pela ausência de valores, ou melhor, em uma sociedade em que há tendência a viver apenas o presente, 0 aqui e agora, o individualismo a serviço de um consumismo que consagra o shopping como a grande catedral, espaço social por excelência.

A mídia, mais do que nos informar sobre o mundo, o refaz à sua própria maneira, para o consumismo construído e permanentemente reconstruído por ela. Isto significa, entre outros aspectos, que lidamos mais com a imagem. do que com o objeto, com a reconstrução do fato, filtrado pelas diversas fontes que o reconstroem ou deformam, para melhor manipular a opinião pública. Com a massificação das imagens, mensagens e comportamentos, a sensibilidade é fragilizada e a identidade pessoal, familiar e social evapora-se. Por isso, é fundamental trabalhar uma metodologia que resgate a memória e a identidade social/cultural dos alunos.

Múltiplas são as interpretações sobre fatos, pessoas e idéias, pois diferentes são os interesses, valores e concepções de quem as elabora. É importante exercitar o aluno neste processo de percepção do lugar social de quem fala e no confronto destas posições. Iniciar o aluno no processo de "leitura do mundo", seja por meio da palavra escrita, artefatos, imagens, num movimento de "aprender a ver", trabalhando com diferentes linguagens.

\section{Conceitos norteadores}

Estes princípios constituem os alicerces de uma construção pedagógica e se articulam com conceitos que viabilizam a concretização de uma prática conseqüente. Fundamental, a explicitação de, pelo menos, aqueles mais

6 SANTOS, Jair. O pós-moderno. São Paulo, Brasiliense, 1987. 
recorrentes, tais como: História/memória, cultura, representação, fonte, leitura, competências/habilidades, e aprendizagem significativa.

Historria entendida como prática social, constantemente construídal reconstruída por sujeitos diferenciados, em várias dimensões do social. Situarse criticamente no campo da memória/história, que põe em disputa os significados do passado/presente/futuro, colocando em discussão a experiência e as referências históricas dos alunos em diálogo com as experiências e referenciais dos sujeitos históricos.

0 valor histórico do passado lembrado apoia-se em três pontos fortes: proporciona informação significativa e, por vezes, única do passado; pode transmitir a consciência individual e coletiva que é parte integrante deste mesmo passado; e fornece uma perspectiva histórica que nos permite avaliar 0 significado, a longo prazo, da própria história.

Paul Thompson, no seu livro A Voz do Passado, conclui q ie a memória não é o resgate individual de um passado que se conserva intacto e que pelo exercício mnemônico nos alcança. É reconstrução elaborada a partir de parâmetros que são resultados da relação entre o homem e sociedade. A reconstrução do passado depende essencialmente da integração do indivíduo a um grupo social que compartilhe suas experiências e cuja existência dá sustentação à sua memória. Neste sentido, memória individual é, ao mesmo tempo, memória social. É uma ação coletiva pois, embora o indivíduo seja 0 memorizador, a memória somente se sustenta no interior de um grupo. As narrativas transmitem a verdade simbólica e não os fatos do acontecimento descrito.

Os estudos sobre memória, como os de Pierre Nora, sinalizam um mal estar de nosso tempo: o cidadão contemporâneo vai se dando conta de uma ruptura definitiva com o passado e 0 sentimento tradicional de continuidade entre o passado e o presente vai se tomando cada vez mais residual. Hoje, a memória coletiva encontra-se refugiada em lugares poucos visíveis, preservada por meio de rituais e celebrações, em que alguns grupos a mantém resguardada do assalto da história, ou em lugares mais imperceptíveis ainda, como em gestos, hábitos ou silêncios. Essa nova percepção de ruptura tem gerado novos suportes da memória, com os quais se possa preservar a continuidade do passado e do presente, em um tempo onde a mundialização, a massificação e o fenômeno da mídia rompem com o equilíbrio e com os suportes coletivos da memória, tal como existiram nas sociedades pré-industriais. 
História e Memória relacionam-se e diferenciam-se. 0 tempo da história é o tempo das mudanças, o da memória coletiva é o da permanência.

A memória é a vida, sempre guardada pelos grupos vivos e em seu nome, ela está en evolução permanente, aberia à dialética dảa lembrançae do esquecimento, inconsciente de suas deformações sucessivas e de súbitas revitalizações. À história é reconstrução sempre problemática e incompleta daquilo que já não é mais. A memória é um fenôneno sempre atual, una ligação do vivido com o eterno presente; a história é uma representação do passado?

Tudo que fazemos está marcado profundamente por nossas concepções. São elas que, consciente ou inconscientemente, orientam nossas opções, práticas, interpretações. Com relação ao professor, são as suas concepçôes de homem, de história, educação, ensino-aprendizagem, que orientam sua proposta de curso, os temas a serem selecionados, a forma de abordagem, a opção metodológica.

0 homem é um ser histórico, social, determinado e determinante, condicionado e condicionante, produtor e produto da cultura. Os sujeitos vivenciam diferentemente o tempo vivido, ou seja, vivenciam diferentes experiências de vida. Por exemplo, a docência é diferentemente vivenciada por cada professor. Lecionam em instituições diversas, com prioridades e intencionalidades distintas. Diversos são os niveis com os quais trabalham, diferentes são a faixa etária e a classe social dos alunos.

O ser humano participa de diversos grupos de indivíduos, diferenciados por sua etnia, classe social, linhagem familiar, religiosidade, participação em um determinado território comum. Essas diferentes configurações grupais estruturam variadas maneiras de ver, perceber e transformar o ambiente à sua volta. À medida que ele é agente das relações sociais e culturais mais diversas, também relaciona-se de modos variados. Os sujeitos ocupam e falam de diferentes espaços sociais, com diferentes projetos, interesses e prioridades.

As dimensões temporal e espacial também estão sujeitas à essas produções e determinações humanas, mediadas que são pelas culturas. Neste sentido, o

\footnotetext{
7 DECCA, Edgar. "Memónia e Cidadania". In: 0 direito da Memória: patrimônio histórico e cidadania. DPH, S.P., 1992, p.130 e 131.
} 
tempo histórico e o espaço geográfico são social e culturalmente construídos, consolidando os diversos modos de conceituar e de estabelecer contatos com 0 meio circundante.

Cultura, na concepção de E. P. Thompson, é todo modo de luta e de organização social, expresso nas experiências cotidianas que se evidenciam na forma de viver, pensar e agir. Cultura não como "coisa" que se usa, manipula, consome, mas como "algo que se cria". Cultura não como algo fechado, estático, mas dinâmica, multiforme. ${ }^{8}$

Na cultura, as diferentes dimensões são perpassadas pelo conflito e pela contradição, vinculados, inclusive, à desigualdade social. No movimento da permanência/transformação cultural, vamos construindo nossa identidade pessoal e social. Devemos pensar as práticas como cultura objetivada e subjetivada, conjunto de obras, realizações, instituições, inclusive usos e costumes, assim como suas representações, como o faz Roger Chartier. ${ }^{9}$

A história trabalha com narrativas. Nossas convenções instituem o real e nós trabalhamos sobre esta construção. Nossas representações/interpretações traduzem nossas experiências. 0 que está em jogo é a linguagem como mediadora/passagem entre as ações e suas representações/interpretações. As ações simbólicas são configuradas como textos a serem lidos ou linguagens a serem decodificadas.

A tensão fundamental da obra de Roger Chartier é, por um lado, uma permanente interrogação "sobre a possibilidade de ir do discurso ao fato, o que o leva a questionar a fonte enquanto testemunho de uma realidade de que esta seria mero instrumento de mediação". Daí a tendência para pensar a realidade através das suas representações e considerá-las de múltiplos sentidos. 0 autor constata a existência de práticas sociais irredutiveis à representações, porque revestidas de uma lógica própria. "Resolver esta tensão implica tornar operatórias a noção de leitura e o conjunto de formas de apropriação, as quais permitem pensar simultaneamente a relação de conhecimento, em particular os procedimentos com as fontes, e o conjunto dos actos de relação, comprometedorés de práticas e de representações". ${ }^{10}$

8 THOMPSO,E.P. A Formação da Classe Operária Inglesa. R. J.: Paz e Terra,1987.
9 CHARTIER, Roger. A História Cultural: entre práticas e representações. Lisboa, Difel, 1990. 
Para chartice, o conceito de representacão manifesta a ursto notre dois sentidos:

"por un lado, a representação cono dando a ver uma coisa ausente, a que supöe una distinção radical entre aquilo que representa e aquilo qqué representado, por outro, a representaça como exibigão de uma presenga, como apresentaçäo pública de algo ou de alguém. No primeiro sentido, a representação é instrumento de un conhecimento mediato que faz ver um objeto ausente através da sua substivuição por uma 'imagen' capaz de o reconstituir em memória e de o figurar tal como ele é. Algumas dessas imagens são bem materiais e semelhantes, como os bonecos de cera, de madeira (...). Outras, porém, são pensadas num registro diferente: o da relação simbólica (..) representação (..) das inagens ou das propriedades das coisas naturais. (...) 0 leão é o símbolo do valor, a esfera, o da inconstancia (...) Uma relação compreensivel é, então, postulada entre o signo visível e o referente por ele significado - o que não quer dizer que seja necessariamente estável e unívoca (...) note-se que a dstinção fundamental entre representação e representado, entre signo e signficado, é pervertida pelas formas de teatralização da vida social de Antigo Regime. Todas elas tên em vista lazer com que a identidade do ser não seja outra coisa senão a aparência da representação, isto é, que a coisa não exista a näo ser no signo que a exibe"."

A noção de representação, segundo Chartier, permite articular três modalidades da relaça con o mundo social: primeiramente, o trabaho de classificação e de delimitacão, que produz as configurações intelectuais múltuplas, através das quais a realidade é contraditoriamente construída pelos diferentes grupos; as práticas que visam fazer reconhecer uma identidade social, uma maneira propria de estar no mundo e, portanto, significar, simbolicamente, um estatuto e uma posição; por fin, as formas institucionalizadas e objetivadas graças as quais as representaçöes marcam, sempre ede forma visivel, a existência do grupo, da classe ou da comunidade.

\footnotetext{
${ }^{10}$ CHARTTWR, Roger. A História Cultural: entre práticas e representaçóes. Lisboa, Difel, 1990, p.11.

11 CHARTIER, Roger. Obra citada, p.20 e 21.
} 
A problemática do "mundo como representação", moldado através das séries de discursos que 0 apreendem e 0 estruturam, segundo 0 autor, nos leva a uma reflexão sobre o modo como uma figuração desse tipo pode ser apropriada pelos leitores dos textos ou das imagens que dão a ver e a pensar o real. Daí o interesse manifestado, por Chartier, sobre o processo pelo qual é historicamente produzido um sentido e diferentemente construída uma significação. "Como é que uma configuração narrativa pode corresponder a uma re-figuração da própria experiência". As modalidades do agir e do pensar devem ser articuladas à "interdependência que regulam as relações entre os indivíduos e que são moldados, de diferentes maneiras em diferentes situações, pelas estruturas do poder. Pensar assim a individualidade nas suas variações históricas equiivale não só a romper como conceito de sujeito universal, mas também a inscrever num processo a longo prazo - caracterizado pela transformação do e das relações entre os homens - as mutações das estruturas da personalidade."12

É importante identificar a maneira como nas práticas, nas representações ou nas produções, se cruzam e se imbricam diferentes formas culturais.

A preocupação com a abrangência da atividade humana encoraja a interdisciplinaridade. A crise do paradigma tradicional da escrita da história apresenta, para o novo paradigma, problemas de conceituação. A preocupação com o cotidiano, "com o mundo da experiência comum (mais do que a sociedade por si só ) como seu ponto de partida juntamente com uma tentativa de encarar a vida cotidiana como problemática", ${ }^{13}$ remete-nos, entre outros, para os problemas das fontes e métodos. A evidência oral, a fotografia, as imagens em geral, estão quase atingindo a sofisticação da crítica do documento escrito. 0 importante é ressaltar o valor, especificidades e limitações das fontes, cabendo ao historiador/professor de história, mediante o seu tema e sua problemática, selecioná-las e interpretá-las adequadamente. Elas se completam e, dependendo da pesquisa, certas fontes podem ser mais "preciosas" do que outras. 0 problema está em como trabalhá-las, independentemente de serem escritas, orais ou visuais.

0 estudo da memória nos ensina que todas as fontes históricas estão impregnadas de subjetividade. Precisamos questionar nossas interpretações

12 CHARTIER, Roger. Obra citada, p. 23-25.

13 BURKE, Peter (org.)- A escrita da História. São Paulo: Editora Unesp, 1992, p.23.

HisTória \& Ensino, Londrina, v. 9, p. 109-132, out. 2003 
confrontando-as com outras fontes. Por outro lado, precisamos estar atentos a uma observação de Paul Thompson: as tradições orais são documentos do presente, porque são narradas no presente. Contudo, trazem também em si, ao mesmo tempo, uma mensagem do passado. Não se pode negar que haja nelas quer o presente, quer o passado. Ignorar uma dessas dimensões, é mutilar a tradição e constitui uma posição reducionista.

Para explicitar o significado da leitura, confrontarei duas posições antagônicas e seus desdobramentos na prática pedagógica. Uma é a leitura entendida como decodificação mecânica de signos, por meio de aprendizado estabelecido a partir do condicionamento estímulo-resposta. 0 conhecimento da língua seria suficiente para a leitura se efetivar. Bastaria superar o estágio da alfabetização para termos um leitor. Outra é a leitura entendida como processo de compreensão abrangente, cuja dinâmica envolve componentes sensoriais, emocionais, intelectuais, culturais, econômicos e políticos. 0 conhecimento da língua não seria suficiente para a leitura se efetivar, pois ela implica em todo um sistema de relações interpessoais e entre as várias áreas do conhecimento, da expressão humana e das suas circunstâncias.

Estas conceituações trazem implicações sobre o significado de texto. Para a da decodificação - texto é só o escrito, entendido como um conjunto de signos. Para o do processo de compreensão, texto é toda mensagem, em qualquer tipo de linguagem: escrita, sonora, imagética, gestual. Para a decodificação, o significado do texto é algo que se dá de imediato à leitura do texto, pois é uma simples decifração do código lingüistico. Para a compreensão, o sentido de um texto é algo que antecede ao contato do leitor com o texto. Isto significa dizer que o leitor preexiste à descoberta do significado das palavras escritas. 0 leitor foi se configurando no decorrer das experiências de vida, desde as mais elementares e individuais até às decorrentes do intercâmbio com seu mundo pessoal e cultural. O significado do texto, portanto é um processo de descoberta a partir do seu contexto pessoal e cultural.

Precisamos estar atentos ao selecionar um texto ou documento para 0 trabalho em sala de aula, porque entre outras razões há vários níveis de leitura que interferem no aprendizado. Podemos identificar três níveis de leitura: a leitura sensorial, emocional e a racional. A leitura sensorial envolve, como o próprio nome diz, os órgãos do sentido: tato, visão, olfato, audição. É uma resposta imediata às exigências e ofertas que o mundo apresenta, não sendo, 
portanto, elaborada. Começa na infância e nos acompanha por toda a vida. Para as crianças e os analfabetos é essa leitura que conta. As características sensíveis do texto como impressão, diagramação, tamanho da letra, quantidade de páginas, dificultam ou facilitam a leitura. A leitura emocional fica no terreno das emoções, no qual as coisas ficam, por vezes, ininteligíveis, escapando ao controle do leitor. Este se vê envolvido pelas armadilhas do inconsciente e, nesta leitura, podem surgir entraves que marcam definitivamente 0 terceiro nível de leitura.

A leitura racional, por sua vez, lida com o elemento racional. Acrescenta à leitura sensorial e emocional, pelo fato de estabelecer uma ponte entre 0 leitor, o texto e o contexto. Propicia uma articulação entre o conhecimento do leitor, e a reordenação/re-significado do mundo objetivo. Implica em um mergulho na tessitura do texto. Nenhum destes três níveis existe em "estado puro", mas em termos de possível predominância. Como a leitura é dinâmica e circunstanciada, esses três níveis são interligados ou mesmo simultâneos, sendo, um ou outro, privilegiado, segundo as experiências, expectativas, necessidades ou interesses do leitor e das condições do contexto no qual ocorre a leitura. 0 homem lê como em geral vive, num processo permanente de interação entre sensações, emoções e pensamentos. ${ }^{14}$

Roger Chartier, no seu livro À beira da Falésia, questiona a concepção segundo a qual o sentido de um texto estaria nele escondido. Afirma, apoiado em Michel de Certeau, que a significação "é produto de uma leitura, de uma construção de seu leitor". Este inventa nos textos algo diferente da intenção do autor. Combina seus fragmentos e organiza uma "pluralidade indefinida de significações". Os textos "não podem então ser apreendidos nem como objetos, cuja distribuição bastaria determinar, nem como entidades, cuja significação seria universal. Devem ser relacionados à rede contraditória das utilizações que os constituíram historicamente. 0 que levanta, evidentemente, duas questões: o que significa ler? Como resgatar as leituras antigas ?"15

Com as transformações tecnológicas, sociais e culturais, uma questão prática, relacional, se impõe com grande evidência. Temos muitos problemas

\footnotetext{
${ }^{14}$ MARTINS, Maria Helena. O que é a Leitura. S.P., Brasiliense, 1984, 4aedição, p.36-69.

${ }^{15}$ CHARTIER, Roger. À beira da falésia: a história entre incertezas e inquietude. Porto Alegre: Editora Universidade/UFRGS, 2002, p.54.
} 
a resolver, muitas decisões a tomar, muitos procedimentos a aprender. Isso não significa, obviamente, que dominar conceitos deixou de ser importante. Vai-se à escola para adquirir conhecimentos ou para desenvolver competências? Conhecimentos e competências são complementares, mas pode haver entre eles um conflito de prioridade, dado o pouco tempo do trabalho em sala de aula. Penso que, como afirma Perrenoud ${ }^{16}, 0$ que está em jogo é o debate entre duas visões de currículo: uma postura que defende uma ampla acumulação de informações, conceitos, sem preocupar-se com sua mobilização em determinada situação, confiando que as competências ocorrerão "naturalmente" na vida profissional. Ou uma posição que entende que deve haver a seleção e/ou limitação dos conteúdos conceituais a serem trabalhados, para que se possa "exercitar no âmbito escolar a mobilização de conhecimento em situação complexa, ou seja, provocar sua integração operacional em uma competência".

0 desafio, hoje, é coordenar o ensino de conceitos e gestão de sala de aula, com aprendizagens e desenvolvimento de procedimentos, valores e atitudes. Ou seja, trabalhar com competências "não significa dar as costas aos conteúdos conceituais" mas, simultaneamente, trabalhạr os conteúdos procedimentais (competências e habilidades) e os conteúdos atitudinais.

Segundo Perrenoud, conhecimento são representações da realidade, que construímos e armazenamos ao sabor de nossa experiência e de nossa formação. Competência é "uma capacidade de agir eficazmente em um determinado tipo de situação, apoiada em conhecimentos, mas sem limitar-se a eles". Isto porque as competências "utilizam, integram ou mobilizam os conhecimentos", num momento preciso para a solução de um dado problema. As competências são, pois, "complexas operações mentais cuja orquestração só pode construir-se ao vivo, em função tanto de seu saber e de sua perícia quanto de sua visão da situação". ${ }^{17}$

Perrenoud questiona a postura que considera a competência como uma faculdade genérica, uma potencialidade de qualquer mente humana.

\footnotetext{
16 PERRENOUD, P. Construir competências desde a escola. Porto Alegre, Artes Médicas, 1999, p 10.

17 PERRENOUD, P. Obra citada, p.7 e 8.
} 
As potencialidades do sujeito só se transformam em competências efetivas por meio de aprendizados que não intervêm espontaneamente, por exemplo, junto com a maturação do sistema nervoso, e que também não se realizam da mesma maneira em cada indivíduo. Cada um deve aprender a falar, mesmo sendo geneticamente capaz disso. As competências, (...) são aquisições, aprendizados construídos, e não virtualidades da espécie. ${ }^{18}$

Os termos valorizados pelo autor para caracterizar as competências são: tomada de decisão, mobilização de recursos e utilização de esquemas.

Tomada de decisão no sentido de que a competência refere-se ao julgamento ou interpretação, a partir de um conjunto de indicadores ou fatores presentes em uma determinada situação e que implicam uma decisão. Para isso, a competência irá mobilizar uma série de recursos disponíveis, afetivos, sensoriais, cognitivos, entre os quais o conhecimento, para essa tomada de decisão. "Em sua concepção piagetiana, o esquema, como estrutura invariante de uma operação ou de uma ação, não condena a uma repetição idêntica. Ao contrário, permite, por meio de acomodações menores, enfrentar uma variedade de situações de estrutura igual. (...) 0 esquema é uma ferramenta flexível". ${ }^{19}$

Segundo Perrenoud, nascemos com alguns esquemas hereditários e construímos outros ao longo da vida. Os esquemas nos permitem mobilizar conhecimentos, informações para enfrentar uma situação. Entretanto, para 0 autor, uma competência não é um simples esquema, "mas orquestra um conjunto de esquemas. Um esquema é uma totalidade constituída, que sustenta uma ação ou operação única, enquanto uma competência com uma certa complexidade envolve diversos esquemas de percepção, pensamento, avaliação e ação, que suportam inferências, antecipações, transposições analógicas, generalizações, apreciação de probabilidades, estabelecimento de um diagnóstico a partir de um conjunto de índice, busca das informações pertinentes formação de uma decisão, etc "20

As orientações do ENEM (Exame Nacional do Ensino Médio) propõem

\footnotetext{
${ }^{18}$ PERRENOUd, P. Obra citada, .p.21.

${ }^{19}$ PERRENOUd, P. Obra citada, p.23.

${ }^{20}$ PERRENOUD, P. Obra citada, p. 24 .
} 
que a competência seja entendida em três modalidades: como condição prévia do sujeito, como condição do objeto, independente do sujeito que o utiliza, e como competência relacional. ${ }^{21}$

Competência como condição prévia do sujeito, herdada ou adquirida. É comum definir competência como capacidade de um organismo. Saber respirar, falar, por exemplo, são capacidades herdadas. Nascemos com competência comunicativa, isto é, herdamos nossa aptidão para a linguagem. Ao mesmo tempo, temos de adquirir competência em uma ou mais línguas, pois essas não são herdadas, mas aprendidas e se constituem em patrimônio de nossa cultura e de nossa possibilidade de comunicação. Nesse caso, competência e desempenho. são dimensões diferentes. Ter capacidade de caminhar não é caminhar.

Competência, nesse primeiro sentido, significa, muitas vezes, o que se chama de talento, dom ou extrema facilidade para alguma atividade. Essa primeira forma de competência não significa apenas formas de aquisição, mas também pode se referir a uma perda - permanente ou transitória - de competência. Por exemplo, podemos perder ou diminuir nossa capacidade respiratória ou condição para realizar uma certa tarefa. Em caso de acidente, podemos perder nossa possibilidade de locomoção. Da mesma forma, um professor pode, por diversos fatores, perder sua competência didática.

Competência como condição do objeto, independente do sujeito que 0 utiliza. Refere-se à competência da máquina ou do objeto. Por exemplo, a competência ou habilidade de um motorista não tem relação direta com a potência de seu automóvel. 0 mesmo acontece com relação aos computadores e seus usuários. Uma coisa é nossa condição de operar um certo programa. Outra é a potência do computador, sua velocidade de processar informações, memória. Na escola, essa forma de competência está presente, por exemplo, quando julgamos um professor pela "competência" do livro que adota, da escola em que leciona.

Competência relacional. Essa terceira forma de competênciaéinterdependente, ou seja, não basta ser bom conhecedor de uma matéria, não basta possuir objetos e/ ou material, livros adequados, pois o importante aquié "como essesfatores interagem". A competência relacional expressa esse jogo de interações.

${ }^{21}$ MACEDO, Lino. Eixos Teóricos que estruturam o ENEM. I Seminário do Exame Nacional de EnsinoMédio. MEC/INEP. Brasília, outubro de 1999, p.9-12. 
Numa partida de futebol, para fazer um gol, não basta que 0 jogador saiba chutar para o gol, fazer embaixada, correr com a bola no pé; é necessário que saiba coordenar tudo isso no momento da partida e fazer o gol. Numa conferência, a qualidade do texto não é condição suficiente para que 0 conferencista atinja os objetivos, énecessário fazer uma boa leitura, considerando o ritmo, as pausas e, sobretudo, as expectativas e reações da platéia etc.

A situação de jogo é um bom exemplo de competência relacional, pois essa forma sempre se expressa em um contexto de interdependência. 'Não se ganha o jogo na véspera', como se diz usualmente. Na véspera, há muitas ações que se podem realizar (treinar, estudar outras partidas, etc.), mas são as leituras ou interpretações, no momento do jogo propriamente dito, as tomadas de decisão, as coordenações entre ataque e defesa que definirão as possibilidades de ganhar ou perder. (...) A sala de aula é um bom exemplo disso. Muito se pode e deve fazer previamente: estudar, preparar e selecionar materiais, escrever o texto ou definir o esquema a ser seguido. Mas há outros fatores que só podem e devem ser definidos no momento da aula, em função de outros que não se podem antecipar, justamente porque são construídos no jogo das interações entre o professor, seus alunos e os materiais de ensino $0^{22}$.

As múltiplas tarefas de que um professor deve cuidar, de preferência ao mesmo tempo, implica em mobilizar e coordenar os múltiplos aspectos que concorrem simultaneamente. Daí, a imagem da competência relacional como a de um jogo que não se ganha na véspera mas durante o próprio ato de jogar, dependente de fatores que não podem ser criados antes ou depois do jogo. Malícia, domínio de si mesmo, poder interpretar e tomar decisões no contexto da situação-problema, coordenar os múltiplos aspectos que concorrem simultaneamente, são fatores importantes para o que se analisa como competência relacional.

A competência relacional supõe uma abertura para a diversidade. Diversidade de pontos de vista, múltiplas formas de se expressar, variabilidade de contextos. Pode-se argumentar de diferentes modos, há abertura para soluções divergentes, há espaço para diferenças.

${ }^{22}$ MACEDO, Lino. Obra citada, p.11 e 12. 
Na perspectiva da competência relacional, mais importante é o processo de jogar, éa qualidade do modo como se joga. Ora, essa dimensão do jogo écooperativa, não é competitiva. E marcada pela interdependência. No jogo, cada parte depende da outra. Se um jogador não movimenta sua peça, o outro, na vez seguinte, não poderá fazer sua jogada. Todos estão submetidos às mesmas regras, ao mesmo tabuleiro. Portanto, o jogo, como processo, é um exercício de interdependência, de cooperação, não de competição, mesmo em jogos competitivos.

A competência relacional é muito importante em uma visão construtivista do processo de aprendizagem escolar. Para essa visão, a interação caracteriza-se por trocas que podem gerar, em sua própria realização, uma tensão. Na visão construtivista, como em termos de competência relacional, o que interessa não é o que marca as diferenças, mas o que as coordena. 0 desafiö, do ponto de vista relacional, é como comunicar, em um desses tempos, algo que seja pertinente e interessante sobre o assunto. Esse é o desafio em uma perspectiva relacional. Há diferenças que separam, há diferenças que aproximam. Na competência social, são as diferenças passíveis de serem integradas, coordenadas, que interessam.

As três formas de competência, na prática, não se anulam, necessariamente, pois referem-se à dimensões diferentes e complementares de uma mesma realidade. 0 elemento surpresa que caracteriza um dos aspectos da competência relacional não deve ser confundido com improvisação ou impossibilidade de antecipação.

A diferença entre competência e habilidade, em uma primeira aproximação, depende do recorte. Resolver problemas é uma competência que supõe o domínio de várias habilidades. Saber ler, como habilidade, não é 0 mesmo que saber ler como competência relacional. Em muitas situações, quando temos de ler em público, por exemplo, temos dificuldades para isso. Como coordenar as perspectivas do texto, dos ouvintes e do leitor? Todos conhecemos escritores brilhantes que não são bons conferencistas. Para se comunicar bem em uma palestra, a habilidade de saber ler é uma condição insuficiente, pois há uma conjunção de fatores que são de outra ordem, o que eqüivale a uma competência.

"Para dizer de um outro modo, a competência é uma habilidade de ordem geral, enquanto a habilidade é uma competência de ordem particular, específica. (...) 0 que não quer dizer que competência seja apenas um conjunto 
de habilidades: é mais do que isso, pois supõe algo que se reduz à soma das partes." ${ }^{23}$ A competência é o modo como fazemos convergir nossas necessidades e articulamos nossas habilidades em favor de um objetivo ou solução de um problema, que se expressa num desafio.

As habilidades são, pois, conjuntos de possibilidădes, repertórios que expressam nossas múltiplas e desejadas conquistas. As habilidades são operações ou processos mentais, ações, comportamentos associados ao pensamento, tais como observação, classificação, comparação, interpretação, levantamento de hipóteses, entre outras. São processos mentais que se superpõem, entrelaçamse, sem seqüência hierárquica, pois os limites entre os processos mentais são imprecisos e é difícil estabelecer um esquema de classificação. Mas cada habilidade tem um objeto específico. É preciso tê-lo em mente para elaborar atividades que o desenvolvam. Por exemplo, o significado da observação é distinguir a percepção dos sentidos e a percepção do pensamento. É identificar dados ou fatos. Seu objetivo último é desenvolver a percep̧̧ão das partes para melhor entendimento do todo. Implica perceber a diferença entre opinião, dado ou fato. Observar não é apenas "ver" ou "ouvir". Observar implica a idéia de notar, perceber, discernir e agrupar dados, fatos ou idéias. É uma forma de descobrir informações. ${ }^{24}$

É a consciência que atribui significado aos objetos que nos rodeiam. No âmago da consciência encontra-se a intencionalidade, que é a ponte entre sujeito e objeto. A intencionalidade é a estrutura que dá significado à experiência. É a estrutura de sentido que nos possibilita, sujeitos que somos, a ver e compreender o mundo. Cognição é o processo através do qual o mundo de significados tem origem e a psicologia cognitiva volta-se para o estudo do dinamismo da consciência, ou seja, para o processo pelo qual o homem desenvolve sua "compreensão" do mundo e passa a agir segundo essa compreensão... ${ }^{25}$ Esses significados são pontos de partida para a atribuição de outros significados. Constitui-se então a estrutura cognitiva, ponto básico de ancoragem, do qual derivam outros significados.

\footnotetext{
${ }^{23}$ MACED0, Lino. Obra citada, p.13.

${ }^{24}$ RATHS, Louis e outros. Ensinar a pensar. São Paulo, EPU Editora Pedagógica e Universitária, 1977, p.11-50.

${ }^{25}$ MOREIRA, Marco e MASINI, Elcie. Aprendizagem significativa: a teoria de David Ausubel S.P. :Moraes, 1982, p.1-3.
} 
A aprendizagem significativa é, segundo Ausubel, um processo pelo qual uma nova informação se relaciona com um aspecto significativo do conhecimento do indivíduo. Essa aprendizagem ocorre quando a nova informação ancora-se em conceitos relevantes preexistentes na estrutura cognitiva de quem aprende. Cada disciplina tem uma estrutura articulada e organizada de conceitos que constitui seu sistema de "informaçóes". Podemos, portanto, construir um mapa conceitual de uma disciplina, programa de curso ou mesmo de uma série, partindo dos conceitos mais gerais, significativos, inclusivos, chamado subsunçot ${ }^{26}$, articulando-os aos conceitos subordinados selecionados para 0 trabalho pedagógico. Mapeamos, portanto, um corpo de conhecimento e como todos esses conceitos estarão organizados, progressiva, estrutural e hierarquicamente.

Mapas conceituais são, pois, diagramas indicando relação entre conceitos ou entre palavras que usamos para representar conceitos. A construção do mapa conceitual é subjetiva, uma vez que expressa a valorização e relacionamento dos conceitos selecionados. 0 mapa conceitual auxilia 0 professor a organizar sua programação, assim como diagnosticar seu trabalho. Portanto, constitui um facilitador do trabalho pedagógico, podendo ou não ser desenvolvido com os alunos após o estudo de um tema para ref́letir sobre os conceitos trabalhados.

0 mapa conceitual anexo expressa os conceitos básicos desenvolvidos no ensino fundamental da Escola Nossa Senhora das Graças, onde sou assessora de História. É um trabalho desenvolvido pelas professoras Andréa Monteilato e Conceição Cabrini. As cores representam as respectivas séries do ensino fundamental: preto, indicando os conceitos desenvolvidos na $5^{\text {a }}$ série; vermelho, os desenvolvidos na $6^{a}$ série; verde, na $7^{\mathrm{a}}$ série; e,azul, na $8^{\mathrm{a}}$ série. Os conceitos representação, cultura e tempo e espaço são trabalhados ao longo das séries.

A aquisição de conceitos, para Ausubel, é fruto da psicodinâmica dos aspectos denotativos (atributos criteriais distintivos evocados pelo nome de um conceito) e conotativos (reações atitudinais ou afetivas eliciadas pelo conceito). A formação de conceitos é uma característica da criança em idade pré-escolar, quando ocorre a aquisição espontânea de idéias genéricas por meio da

${ }^{26}$ Conceito subsunçor: idéia âncora, conceitos ou proposição mais ampla que funciona como um subordinador de outros conceitos na estrutura cognitiva e como ancoradouro no processo de assimilação. Idem, p.7. 
experiência empírico-concreta. Consiste de um processo de abstração dos aspectos comuns e essenciais de uma classe de objetos ou eventos que varia contextualmente. A assimilação de novos conceitos ocorre pela percepção de seus atributos criteriais e pelo relacionamento desses atributos com as idéias relevantes já estabelecidas em sua estrutura cognitiva.

Aprender um novo conceito depende da propriedade existente na estrutura cognitiva, do nível de desenvolvimento do aprendiz, de sua habilidade intelectual, da natureza conceitual do conceito, do modo como é apresentado. $\mathrm{Na}$ formação de conceitos, a análise discriminativa de diferentes padrões de estimulo é mais longa e requer mais exemplos e situações variadas. Na assimilação de conceitos, o indivíduo detém-se pouco nesse primeiro item, já que existem conceitos que servem de ancoradouro. A linguagem ocupa um papel facilitador na aquisição de conceitos, sem a qual seria inconcebível, porque a força representacional do símbolos verbais reflete 0 nível do funcionamento cognitivo no processo de conceitualização. A linguagem assegura a uniformidade cultural, o conteúdo, e facilita a comunicação cognitiva interpessoal.

São estes, portanto, os conceitos básicos que auxiliam a tecer os procedimentos que permitem concretizar os princípios teóricos a que aludi no início deste texto.

Estas reflexões expressam o amadurecimento de meu processo de pesquisa, constituindo o "avesso do avesso" de uma prática pedagógica que considero conseqüente. São fruto de intuições reforçadas por pesquisadores de aspectos diferenciados do processo do conhecimento, especialmente do conhecimento histórico.

\section{Bibliografia}

BURKE, Peter (org.).A escrita da História. São Paulo: Editora Unesp, 1992.

CHARTIER, Roger. A História Cultural: entre práticas e representações. Trad. Maria M. Galhardo. Lisboa, Difel, 1990.

CHARTIER, Roger. À beira da falésia: a história entre certezas e inquietude. Trad. Patrícia C. Ramos. Porto Alegre: Ed. Universidade/UFRGS, 2002. 
CIAMPI, Helenice. A História Pensada e Ensinada: da geração das certezas à geração das incortezas. São Paulo, EDUC /FAPESP, 2000.

DECCA, Hdgar. "Memória e Cidadania". o direito da Memória: patrimônio histórico e cidadania. D P H. SP, 1992, p.129-136.

MACEDo, Lino. Eixos Teónicos que estrituram o ENEM. S Seminário do Exame Nacional de Ensino Médio. MEC/NEP. Brasilia, outubro de 1999.

MORIN, Edgar Os Setes Saberes necessários à Educação do Futuro.S.P.Cortez;Brasilia.DF:UNESCO,2000.

MOREIRA, Marco e MASINI, Elcie. Aprendizagem significativa: a teoria de David Ausubel. São Paulo : Moares, 1982.

MARTINS, Maria Helena. O que a Leitura. São Paulo, Brasiliense, 1984.

PERRENOUD, Philippe. Construir competências desde a escola. Porto Alegre, Artes Médicas, 1999.

RATHS, Louis. e outros. Ensinar a Pensar. São Paulo, EPU- Editora Pedagógica e Universitária, 1977.

SANTOS, Jair. O pós-moderno. São Paulo, Brasiliense, 1987.

SCHAFF, Adam. História e Verdade. São Paulo, Martins Fontes, 1986.

THOMPSON, E.P. A Formação da Classe Operária Inglesa. Tradução de Denise Bottman. Rio de Janeiro: Paz e Terra, 1987.

THOMPSON, Paul. A voz do Passado. Rio de Janeiro. Paz e Terra,1992. 

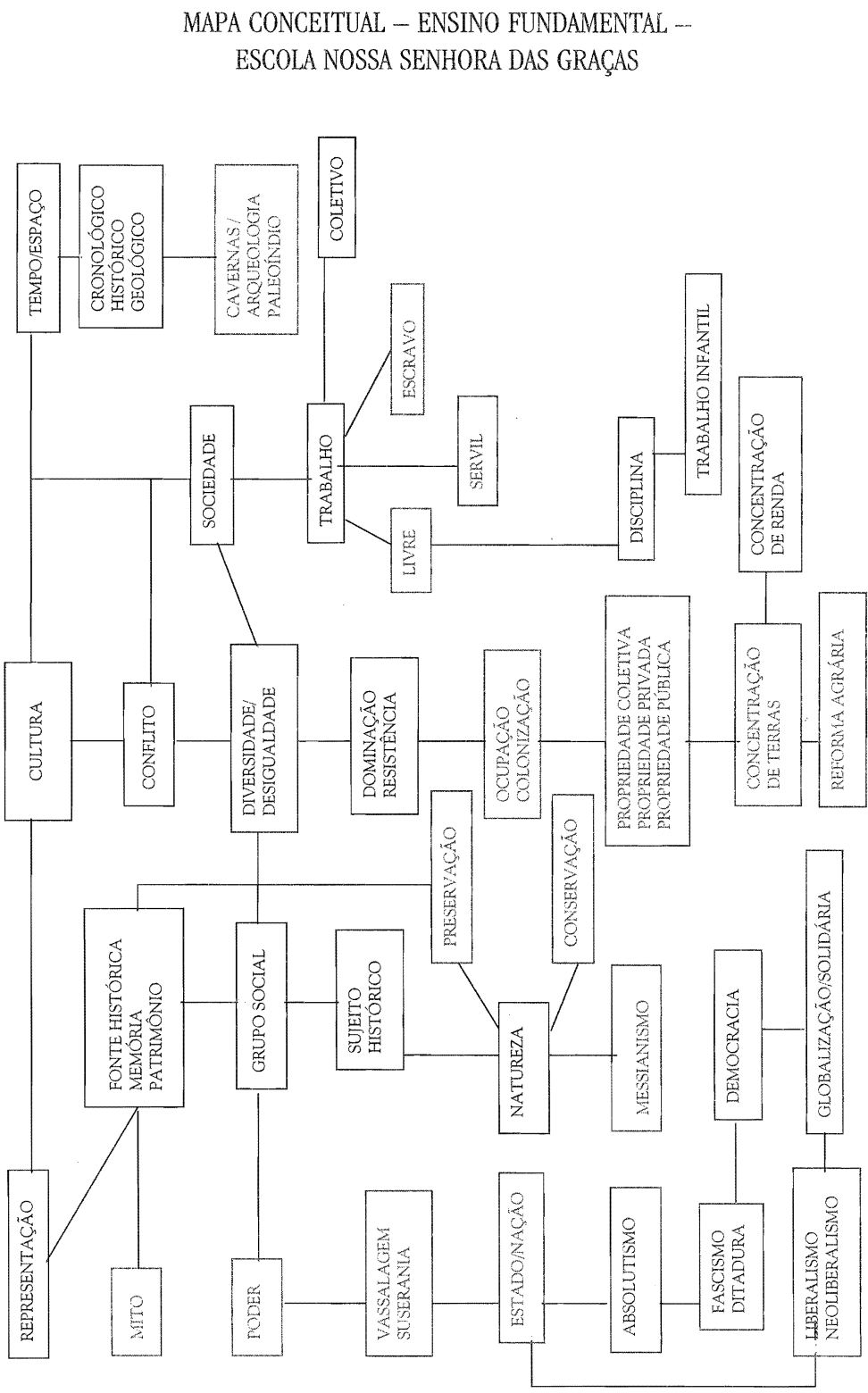

História \& Ensino, Londrina, v. 9, p. 109-132, out. 2003 


\section{ABSTRACT}

The process of historical knowledge and its adequacy to teaching-learning are dealt in this article starting from the concepts that are the basis of a proposition of work which tries to maintain a dialogue between a pedagogy of inclusion which aims at experiencing citzenship and the respect to the differences, and the reality of exclusion which focuses exactly on the distance between theory and experience. Being aware of this contradition I start from the conception of teaching-learning which leads to a more involving pratice. This article aims at considering concepts and conceptions that could orientate the aim of the course for each teacher of History: the relation and difference between History and Memory (as the historical time is the times of changes and the time of collective memory is the one of permance); Culture; Representation (whose notion allows the articulation of three different ways of relation with the social world); Reading; Competences (especially the relation one) and the Significative Leaming.

Key-words: historical knowledge; culture; representation; competences; significative learning; the teaching. of History. 